\title{
Effects of Elevated Withdrawal Rate on the Microstructure and Segregation Behavior of a Nickel-base Single Crystal Superalloy
}

\author{
Zhou Xuefeng $^{1,2}, \quad$ Chen Guang ${ }^{1}, \quad$ Feng Yaya ${ }^{1}, \quad$ Qi Zhixiang ${ }^{1}, \quad$ Li Pei ${ }^{1}, \quad$ Cheng Jialin ${ }^{3}$ \\ ${ }^{1}$ Engineering Research Center of Materials Behavior and Design, Ministry of Education, Nanjing University of Science and Technology, \\ Nanjing 210094, China; ${ }^{2}$ Changshu Institute of Technology, Changshu 215500, China; ${ }^{3}$ Nanjing Institute of Technology, Nanjing 211167, \\ China
}

\begin{abstract}
The effects of withdrawal rate on the microstructure and segregation behavior of a nickel-base single crystal superalloy were investigated. The results indicate that by increasing the withdrawal rate, the primary dendrite arm spacing $\left(\lambda_{1}\right)$, the secondary dendrite arm spacing $\left(\lambda_{2}\right)$ and the size of $\gamma^{\prime}$ precipitates decrease gradually. Moreover, the shape of $\gamma^{\prime}$ precipitates is more regular at higher withdraw rates. Also, the size of $\gamma / \gamma^{\prime}$ eutectic becomes small while the total volume fraction increases. Considering the composition segregation is determined by diffusion time of the constituent elements, when withdrawal rate is elevated, diffusion time of solutes decreases, and the effects of segregation are enhanced.
\end{abstract}

Key words: nickel-base single crystal superalloys; withdrawal rate; solidification microstructure; composition segregation

Due to the excellent high temperature creep performance, nickel-base single crystal superalloys are attractive preference of advanced aero-engine turbine blades ${ }^{[1-6]}$. As known, performance of nickel-base single crystal superalloys is determined by the alloy composition, the melting process of master alloy, the directional solidification (DS) technique and heat treatment schedule. Using seed or by a screw selecting method to prepare single crystals, temperature gradient of the liquid/solid interface and crystal growth rate are the two key parameters for the as-cast microstructure and the final performance $^{[7-11]}$. Therefore, it is very important to investigate the effect of withdrawal rates on the microstructure of nickelbase single crystal superalloys. Moreover, the multi-alloying of single crystal superalloys can lead to severe segregation in the as-cast microstructure and ultimately influences the heat treatment process and the performance of alloy ${ }^{[12-14]}$. In the present paper, the relationships between growth rates of the nickel-base single crystal superalloys, dendrite arm spacings $\left(\lambda_{1}, \lambda_{2}\right), \gamma^{\prime}$ phase, $\gamma / \gamma^{\prime}$ eutectic and composition segregation were investigated. We tried to optimize the process parameters and found an appropriate way to control the as-cast microstructure under a constant temperature gradient.

\section{Experiment}

The nominal composition (wt $\%$ ) of the experimental alloy is $7 \mathrm{Cr}-7.5 \mathrm{Co}-2 \mathrm{Mo}-5 \mathrm{~W}-6.5 \mathrm{Ta}-3 \mathrm{Re}-6.2 \mathrm{Al}$, and the balance is $\mathrm{Ni}$. The master alloy ingots were prepared by water-cold crucible vacuum induction levitation melting. Rod-shaped samples from the ingots were cast into a copper mold by gravity casting. The single crystal bars with a diameter of $8 \mathrm{~mm}$ and a length of $100 \mathrm{~mm}$ were prepared by a seed method using a vacuum induction directional solidification furnace as shown in Fig.1. The DS was carried out for the samples with withdraw velocities $(V)$ of $10,20,50,80 \mu \mathrm{m} / \mathrm{s}$ at the holding temperature of $1823 \mathrm{~K}$. And the deviation between the principal axes and [001] direction was less than $10^{\circ}$. The

Received date: May 05, 2016

Foundation item: Jiangsu Province Key Technology R\&D (industry) Program (BE201217); Science and Technology Innovation Fund Program (CX2011028, CX2011029); Cooperative Innovation Fund of Jiangsu Province (BY2014004-09); Foundation of Jiangsu Key Laboratory of Advanced Structural Materials and Application Technology (ASMA201403).

Corresponding author: Chen Guang, Ph. D., Professor, Engineering Research Center of Materials Behavior and Design, Ministry of Education, Nanjing University of Science and Technology, Nanjing 210094, P. R. China, Tel: 0086-25-84315159, E-mail: gchen@ njust.edu.cn 


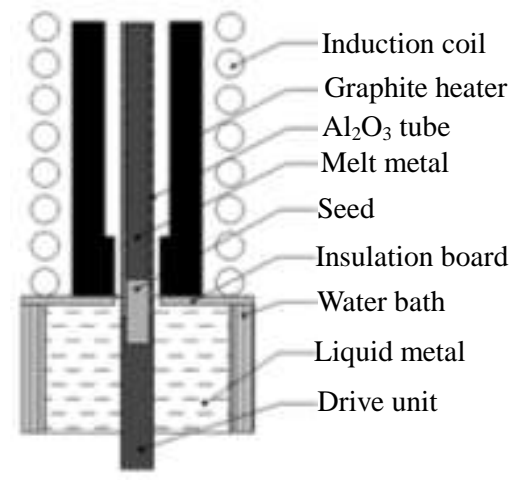

Fig.1 Schematic diagram of directional solidification

resulting samples were polished, and then were etched by a solution of $5 \mathrm{~g} \mathrm{CuSO}_{4}+20 \mathrm{~mL} \mathrm{HCl}+80 \mathrm{~mL} \mathrm{H}_{2} \mathrm{O}$. The as-cast microstructure was observed by Olympus GX41 optical microscope (OM) and ULTRA 55 scanning electron microscope (SEM). The composition segregation coefficient was calculated according to Energy Dispersive X-ray Spectroscopy (EDX). The dendrite arm spacing was calculated by a unit area method and the content of $\gamma / \gamma^{\prime}$ eutectic was measured by a specific area method.

\section{Results and Discussion}

\subsection{Effect of withdrawal rate on the dendrite mor- phology}

The as-cast microstructure at different withdrawal rates is shown in Fig.2a 2d. All the alloys were solidified in a dendrite way and many $\gamma / \gamma^{\prime}$ eutectics were distributed among the interdendritic region. By increasing the withdrawal rates, the size of dendrite spacing decreased. The relationships between withdrawal rates and the dendrite arm spacing $\left(\lambda_{1}\right.$ and $\left.\lambda_{2}\right)$ are shown in Fig.2e and 2f. They exhibit a linear relationship between $\lambda_{1}, \lambda_{2}$ and $v^{-1 / 4}, v^{-1 / 2}$ respectively, consistent with the Hunt fore- casting model ${ }^{[15,16]}$. During the solidification process, fresh grains nucleate and grow in the form of dendrite due to the constitutional supercooling because of the solute enrichment. By increasing the withdrawal rate, the degree of constitutional supercooling of the solid/liquid interface becomes larger, and the radius of the dendrite tip is smaller and sharper. Therefore, the solute atoms shift more easily per unit time which is conducive to diffuse atoms. Moreover, with the enhanced radiating capability of solid solution and the effect of the solidification heat on the each branch, $\lambda_{1}$, and $\lambda_{2}$ gradually become weak.

\subsection{Effect of withdrawal rate on $\boldsymbol{\gamma}^{\prime}$ phase}

Fig.3 shows the morphology of $\gamma^{\prime}$ phase in dendrite and interdendrite at different withdrawal rates. As shown, the size of $\gamma^{\prime}$ phase in dendrite core is smaller. Moreover, by increasing the withdrawal rates, the sizes of $\gamma^{\prime}$ phase both indendrite core and interdendritic region decrease, as shown in Fig.4. However, the morphology of $\gamma^{\prime}$ phase is also more regular and the volume fraction of $\gamma^{\prime}$ phase in dendrite core and interdendrite region is larger at the higher withdrawal rate.

The microstructure of the nickel-base superalloys primarily consists of $\gamma$ matrix and $\gamma^{\prime}$ phase precipitated from the continuous $\gamma$ phase. According to the phase formation rule, $\gamma^{\prime}$ phase is divided into primary $\gamma^{\prime}$ phase and the secondary $\gamma^{\prime}$ phase. The primary $\gamma^{\prime}$ phase nucleates and grows from residual liquid through the eutectic reaction $\left(\mathrm{L} \rightarrow \gamma+\gamma^{\prime}\right)$, and the secondary $\gamma^{\prime}$ phase is precipitated by the eutectoid reaction $\left(\gamma_{1} \rightarrow \gamma_{2}+\gamma^{\prime}\right)$. In the early time of eutectoid reaction, the $\gamma^{\prime}$ phase is precipitated
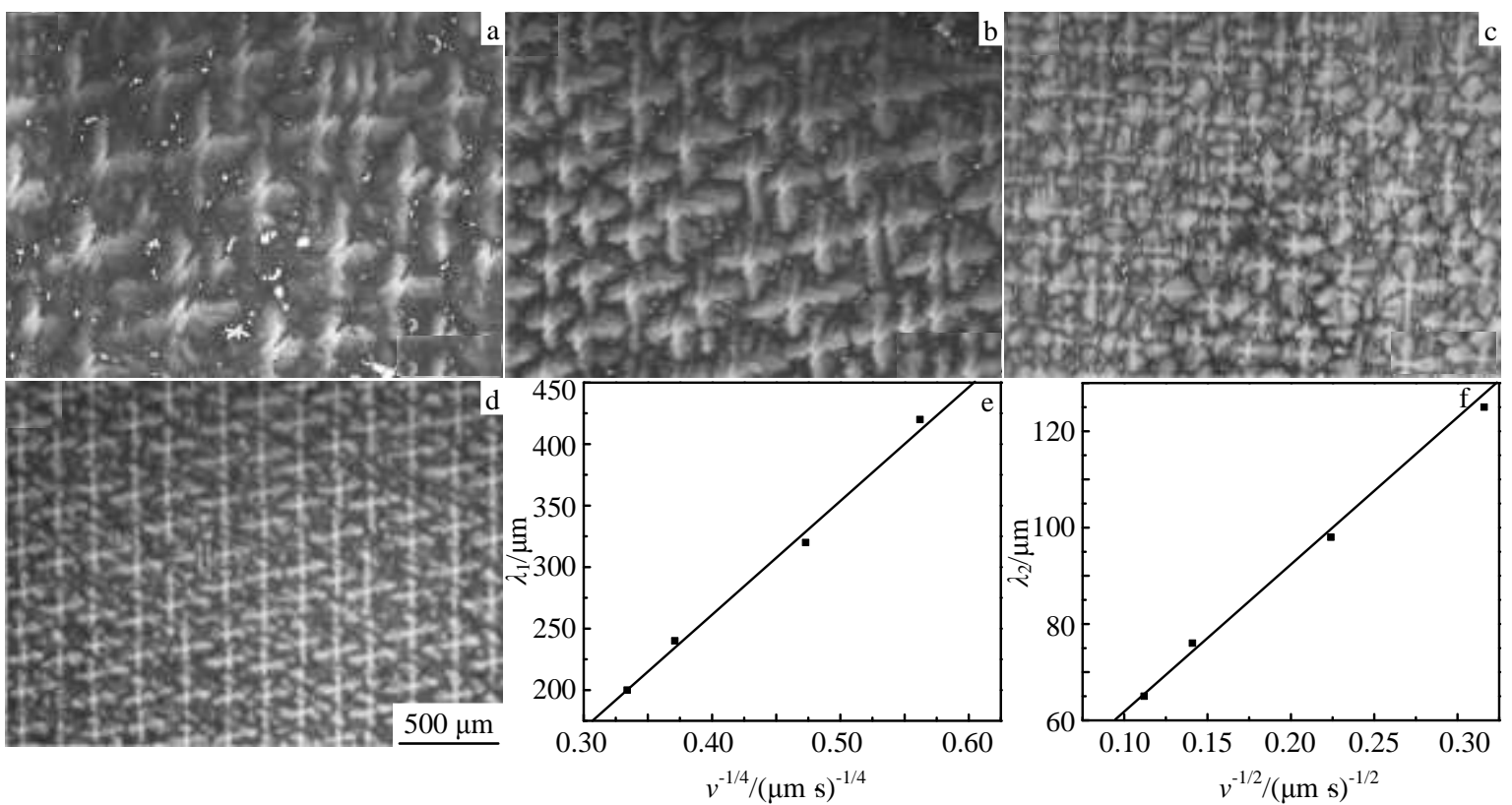

Fig.2 Dendrite morphology at different withdrawal rates: (a) $10 \mu \mathrm{m} / \mathrm{s}$, (b) $20 \mu \mathrm{m} / \mathrm{s}$, (c) $50 \mu \mathrm{m} / \mathrm{s}$, and (d) $80 \mu \mathrm{m} / \mathrm{s}$ and relationship between dendrite spacing $\lambda_{1}$ (e), $\lambda_{2}$ (f) and the withdrawal rates 


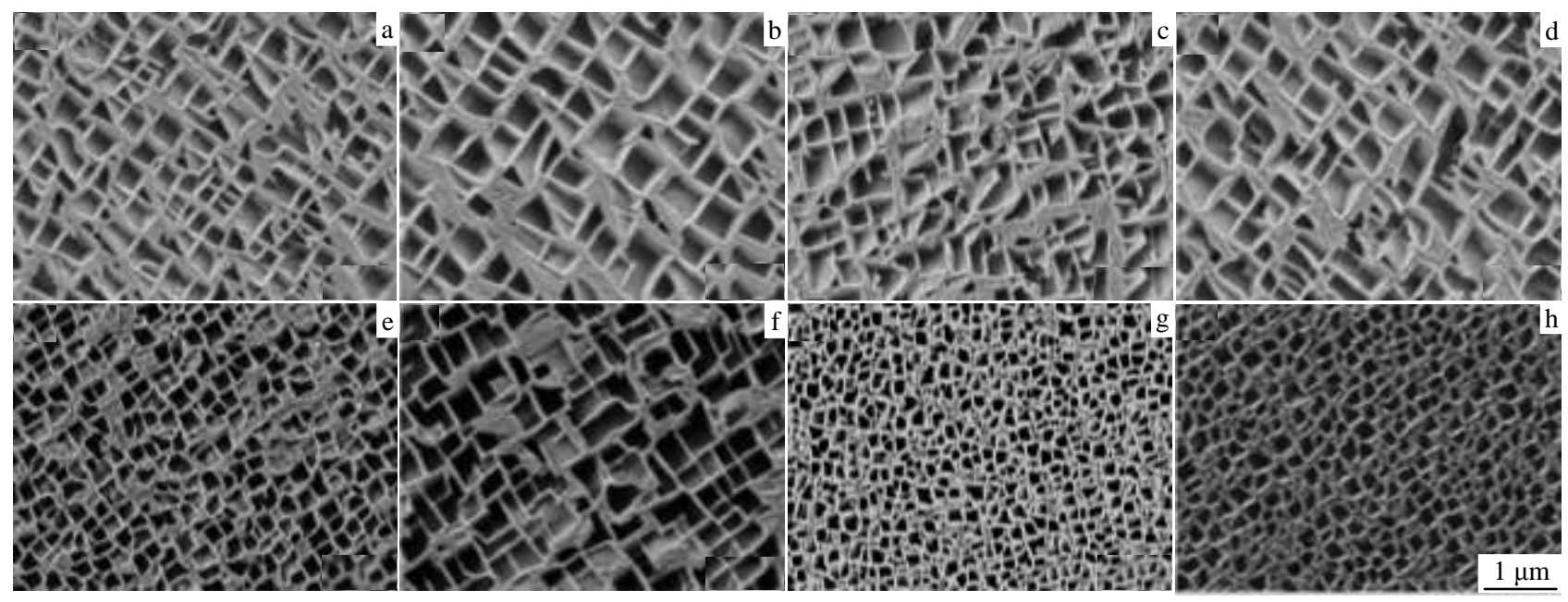

Fig.3 Morphologies of $\gamma^{\prime}$ phase at different withdrawal rates: (a) $10 \mu \mathrm{m} / \mathrm{s}$, dendrite core; (b) $10 \mu \mathrm{m} / \mathrm{s}$, interdendrite; (c) $20 \mu \mathrm{m} / \mathrm{s}$, dendrite; (d) $20 \mu \mathrm{m} / \mathrm{s}$, interdendrite; (e) $50 \mu \mathrm{m} / \mathrm{s}$, dendrite; (f) $50 \mu \mathrm{m} / \mathrm{s}$, interdendrite; (g) $80 \mu \mathrm{m} / \mathrm{s}$, dendrite; (h) $80 \mu \mathrm{m} / \mathrm{s}$, interdendrite

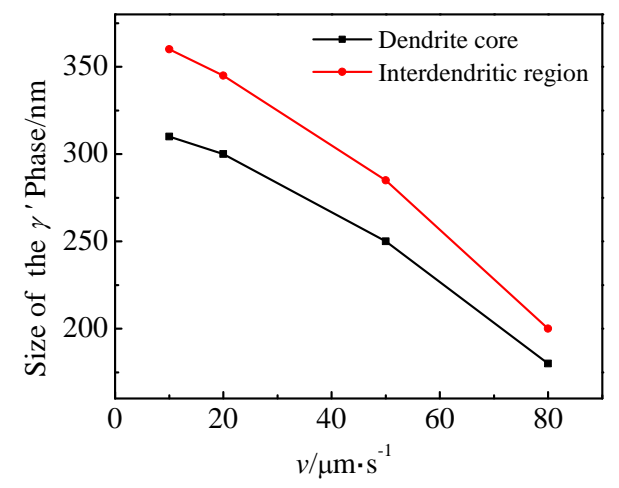

Fig.4 Relationship of withdrawal rate and size of $\gamma^{\prime}$

as spherical, and its critical nucleation energy and critical nucleation radius are as follows:

$$
\begin{aligned}
& \Delta G^{*}=\frac{16 \pi \sigma_{\gamma-\gamma^{\prime}}^{3}}{3\left(\Delta G_{\mathrm{V}}-\Delta G_{\mathrm{s}}\right)^{2}} \\
& r_{\mathrm{c}}=\frac{2 \sigma_{\gamma-\gamma^{\prime}}}{\Delta G_{\mathrm{s}}}
\end{aligned}
$$

Where $\Delta G^{*}$ is critical nucleation energy, $\Delta G_{\mathrm{V}}, \Delta G_{\mathrm{s}}$ are the free energy and the strain energy caused by precipitation of $\gamma^{\prime}$ phase per unit volume, respectively, $r_{\mathrm{c}}$ is critical nucleation radius, and $\sigma_{\gamma-\gamma^{\prime}}$ is interface free energy induced by the change of chemical bond and microstructure. In nickel-base single crystal superalloys, $\gamma$ phase and $\gamma^{\prime}$ phase are fcc structures, and their lattice constants are very close; therefore the $\gamma^{\prime}$ phase is easily precipitated because $\Delta G^{*}$ and $\sigma_{\gamma-\gamma^{\prime}}$ values are quite small.

The DS process is a non-equilibrium solidification, and single crystals are grown in the form of dendrites. The elements $\mathrm{Re}$ and $\mathrm{W}$ gather in the dendrite core and then form single-phase $\gamma$ solid solution, while Al, Ta etc $\gamma^{\prime}$ phase forming elements are enriched in interdendritic region. With the further solidification, the residual liquid transforms into the $\gamma / \gamma^{\prime}$ eutectic. $\Delta G_{\mathrm{V}}$ is proportional to $\Delta X$ which is the supersaturation of the solute in $\gamma$ solid solution. Due to the $\gamma^{\prime}$ phase forming elements such as $\mathrm{Al}$, Ta segregated in interdendritic region, $\Delta X$ in the interdendritic region is much larger than in that in dendrite core, and it results in that the $\gamma^{\prime}$ phase nucleates and grows earlier in the interdendritic region. Therefore, the size of primary $\gamma^{\prime}$ phase in interdendrite is larger than that in dendrite core. In the subsequent cooling process, $\gamma^{\prime}$ phase is precipitated from the $\gamma$ solid solution by the diffusion precipitation transformation. During the phase transition, the morphology of coherent precipitations is determined by the phase interfacial energy and strain energy. If the size of $\gamma^{\prime}$ phase is small, the $\gamma$ and $\gamma^{\prime}$ phase will keep coherent, and the $\gamma^{\prime}$ phase will transform into cubic morphology because the strain energy $\Delta G_{\text {s }}$ plays a major role. While the size of $\gamma^{\prime}$ phase is larger, the interfacial energy $\sigma_{\gamma-\gamma^{\prime}}$ will play a major role. Therefore, the $\gamma / \gamma^{\prime}$ phase interface will lose coherent resistance and the $\gamma^{\prime}$ phase will transform into an irregular shape.

Under the same temperature gradient, the growth time is much longer at a lower withdrawal rate, which has strong influence on the number of $\gamma^{\prime}$ phase in a slight way. Thus the size of $\gamma^{\prime}$ phase is larger with a fewer amount substances and the shape change is not more or less regular; with increasing withdrawal rates, solidification state of the liquid/solid interface deviates from equilibrium solidification gradually, then degree of $\gamma^{\prime}$ phase nucleation supercooling increases sharply with more free energy accumulated from solidified solid phase. Therefore $\gamma^{\prime}$ phase appears in a form of fewer containing with shapes in a more regular way.

\subsection{Effect of withdrawal rate on the $\gamma / \gamma^{\prime}$ eutectic micro- structure}

The typical morphologies of $\gamma / \gamma^{\prime}$ eutectic at different withdrawal rates is shown in Fig.5. It indicates that at a 


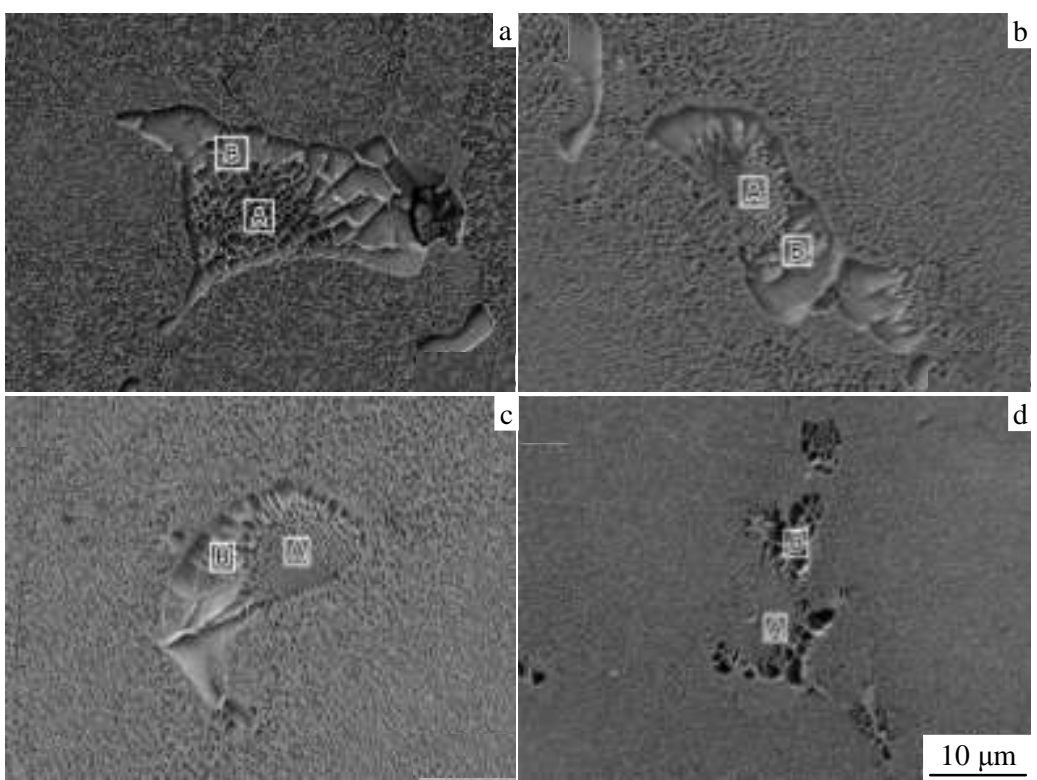

Fig.5 Morphologies of the $\gamma / \gamma^{\prime}$ eutectic at different withdrawal rates: (a) $10 \mu \mathrm{m} / \mathrm{s}$, (b) $20 \mu \mathrm{m} / \mathrm{s}$, (c) $50 \mu \mathrm{m} / \mathrm{s}$, and (d) $80 \mu \mathrm{m} / \mathrm{s}$

lower withdrawal rate, the size of $\gamma / \gamma^{\prime}$ eutectic is larger with a block of primary $\gamma^{\prime}$ phase. With increasing in withdrawal rate, the size of eutectic becomes smaller in a relatively uniform dispersion, the volume fraction of eutectic increases and massive primary $\gamma^{\prime}$ phase decreases gradually. Fig. 6 shows the relationship between withdrawal rates and the content of $\gamma / \gamma^{\prime}$ eutectic. It indicates that the volume fraction of eutectic increases significantly with the withdrawal rate.

The single crystal grows in the form of dendrite in the selected non-equilibrium solidification conditions in the experiment. $\gamma^{\prime}$ phase forming elements such as $\mathrm{Al}$ and Ta are enriched in the interdendritic region. Eutectic appears when liquid composition in the interdendritic region meets eutectic composition. With increasing withdrawal rate, the cooling rate which is not conducive for the diffusion of solute increases so that the supercooling area of the liquid/solid interface increases and the mushy zone is widened. Meanwhile the diffusion of interdendritic liquid is affected because of the secondary dendrite growth; In addition, the increase of segregation makes the eutectic composition of the residual liquid phase increase and eventually leads to the eutectic content increasing.

\subsection{Effect of withdrawal rate on solidification segre- gation}

The segregation coefficient of alloy elements between interdendrite and dendrite core in the nickel-base single crystal superalloys can be expressed as ${ }^{[17]}$ :

$$
k^{\prime}=\frac{C_{\mathrm{DC}}}{C_{\mathrm{ID}}}
$$

Where $k^{\prime}$ is element segregation coefficient, $C_{\mathrm{DC}}$ is the average concentration in dendrite core, and $C_{\mathrm{ID}}$ is average concentration in interdendritic region. Table 1 shows the segregation coefficient at different withdrawal rates. Segregation coefficients of $\mathrm{W}, \mathrm{Re}$, etc. are much more than 1 , which means that elements such as $\mathrm{W}, \mathrm{Re}$ are positive segregation elements. While the segregation coefficients of $\mathrm{Al}$, Ta and Mo are less than 1, indicating that the $\mathrm{Al}, \mathrm{Ta}$ and $\mathrm{Mo}$ are negative segregation elements. The degree of composition segregation decreases significantly at high withdrawal rate. It is interesting to find that $\mathrm{Ni}$ transforms from positive to negative segregation element. The essential reason of the composition segregation is the solute redistribution during the solidification process. The degree of composition segregation is mainly determined by the degree of solute atom diffusion during and after the solidification. At a low withdrawal rate, the segregation behavior of the alloy elements changes approximately according to the solute distribution of single crystals during solidification. The solute distribution in the solid phase diffusion is as follows:

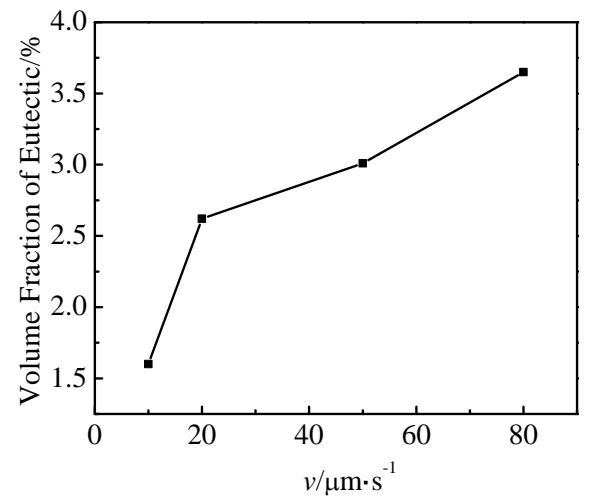

Fig.6 Relationship of the volume fraction of $\gamma / \gamma^{\prime}$ eutectic and withdrawal rate 
Table 1 Effect of withdrawal rate on the segregation coefficient in dendrite core and interdendritic region of the constituent elements

\begin{tabular}{ccccccccccccc}
\hline & Withdrawal rate/ $\mu \mathrm{m} \cdot \mathrm{s}^{-1}$ & $\mathrm{~W}$ & $\mathrm{Re}$ & $\mathrm{Mo}$ & $\mathrm{Cr}$ & $\mathrm{Co}$ & $\mathrm{Ni}$ & $\mathrm{Ta}$ & $\mathrm{Al}$ \\
\hline & 10 & 1.077 & 1.290 & 0.761 & 0.967 & 0.976 & 1.002 & 0.848 & 0.948 \\
Segregation coefficient & 20 & 1.155 & 1.635 & 0.700 & 0.976 & 0.947 & 1.002 & 0.650 & 0.800 \\
& 50 & 1.263 & 1.458 & 0.643 & 0.990 & 0.999 & 0.989 & 0.725 & 0.833 \\
& 80 & 1.521 & 1.801 & 0.837 & 0.972 & 0.902 & 0.944 & 0.639 & 0.858 \\
\hline
\end{tabular}

$$
\begin{aligned}
& C_{\mathrm{s}}=k_{0} C_{0}\left(1-\frac{f_{\mathrm{s}}}{1+\alpha k}\right)^{k_{0}-1} \\
& \text { and, } \alpha=\frac{4 D_{\mathrm{s}} t_{f}}{\lambda^{2}}
\end{aligned}
$$

Where $C_{\mathrm{s}}$ is solute concentration in the liquid-solid interface, $C_{0}$ is solute concentration of the liquid phase, $k_{0}$ is equilibrium partition coefficient of the solute, $f_{\mathrm{s}}$ is volume fraction of solid phase, $\alpha$ is the dimensionless diffusion factor of the solute, $D_{\mathrm{s}}$ is the diffusion coefficient of the solute in the solid phase, $t_{\mathrm{f}}$ is the local solidification time of the alloy and $\lambda$ is the dendrite arm spacing. Therefore, the segregation coefficient is dependent on the segregation, diffusion coefficient, diffusion distance and local solidification time of the alloying elements.

When the cooling rate is low, the distribution coefficient of solute is near to constant, and the degree of composition segregation is mainly determined by the homogenizing effect which is caused by the diffusion of the solute atoms in solid solution. According to Arrhenius equation:

$$
D=D_{0} \exp (-Q / R T)
$$

Where $D$ is the diffusion coefficient, $D_{0}$ is the diffusion constant, $R$ is the gas constant, $Q$ is the diffusion activation energy of per mole atom, and $T$ is the absolute temperature. It can be seen that, with a longer diffusion time, the migration distance of the atoms is longer and the diffusion degree shows frequent change at the same temperature. In addition, the elevating withdrawal rate will make the dendrite arm spacing smaller, thereby the diffusion distance declines and the effect of homogenizing diffusion rises, along with the degree of segregation cutting down. The diffusion time of alloy solute elements plays a dominant role when the withdrawal rate is lower, while the decline of diffusion distance plays a major role when the withdrawal rate is relatively higher. As the withdrawal rate increases, the cooling rate increases and the diffusion time of solute elements in solid solution decreases; afterwards the effect of segregation such as W, Re, Ta, Al is raised. Also, since the formation of the eutectic consumes enough $\gamma^{\prime}$ phase forming elements such as $\mathrm{Al}, \mathrm{Ta}$, the eutectic zone is rich in these elements, while $\mathrm{W}, \mathrm{Re}, \mathrm{Mo}$ and other elements enriches in the frontier of the eutectic. The eutectic gathers fewer $\gamma^{\prime}$ phase forming elements due to the lower of eutectic size, and the segregation degree of Al, Ta at elevated withdrawal rates changes up and down.

\section{Conclusions}

1) All the single crystals grow in the form of dendrite at the present withdrawal rates. However, with increasing the withdrawal rates, the microstructure changes from massive dendrite to tiny dendrite, and the relationship between $\lambda_{1}, \lambda_{2}$ and $v^{-1 / 4}, v^{-1 / 2}$ can be described linearly.

2) The sizes of $\gamma^{\prime}$ phase both in dendrite core and interdendritic region gradually decrease and the shapes change to cube at elevating withdrawal rate. Meanwhile, the size of $\gamma / \gamma^{\prime}$ eutectic decrease and tends to distribute evenly, massive primary $\gamma^{\prime}$ phase also decreases, but the volume fraction of eutectic $\gamma / \gamma^{\prime}$ increases.

3) The segregation of the alloy elements is raised with increasing the withdrawal rates.

\section{References}

1 Cetel A D, Duhl D N. In: Reichman S, Duhl D N, Maurer G eds. Superalloys 1988[C]. Warrendale, PA: TMS, 1988: 235

2 Koizumi Y, Kobayashi T, Yokokawa T et al. Superalloys 2004[C]. Warrendale, PA: TMS, 2004: 35

3 Pineau A, Antolovich S D. Engineering Failure Analysis[J], 2009, 16(8): 2668

4 Tan X P, Liu J L, Jin T et al. Materials Science and Engineering $A[\mathrm{~J}], 2011,528(29): 8381$

5 Qiu C, Wu X, Mei J et al. Journal of Alloys and Compounds[J], 2013, 578: 454

6 Zhou X F, Chen G, Yan S T et al. Acta Metallurgica Sinica[J], 2013, 49(11): 1467

7 Zhao X, Liu L, Yu Z et al. Journal of Materials Science[J], 2010, 45(22): 6101

8 Liu G, Liu L, Ai C et al. Journal of Alloys and Compounds[J], 2011, 509(19): 5866

9 Li L, Overfelt R A. Journal of Materials Science[J], 2002, 37(16): 3521

$10 \mathrm{Xu} \mathrm{C}$, Zhou L Z, Guo J T et al. Chinese Journal of Nonferrous Metals[J], 2011, 21(4): 757

11 Brundidge C L, Van Drasek D, Wang B et al. Metallurgical and Materials Transactions A[J], 2012, 43(3): 965

12 Hosseini S S, Nategh S, Ekrami A A. Materials Science and Technology[J], 2012, 28(2): 213

13 Shi Z X , Dong J X , Zhang M C et al. Journal of Alloys and 
Compounds[J], 2013, 571: 168

14 Balachander M A, Vishwakarma K, Tang B et al. Materials Science and Technology[J], 2011, 27(4): 805

15 Hunt J D. Solidification and Casting of Metals[M]. London: The
Metal Society, 1979: 3

16 Xiaojun T, Yongjun Z, Jianguo L. Rare Metal Materials and Engineering[J], 2012, 41(4): 738 (in Chinese)

17 Caldwell E C, Fela F J, Fuchs G E. JOM[J], 2004, 56(9): 44

\title{
抽拉速率对镍基单晶高温合金组织和偏析的影响
}

\author{
(2. 常熟理工学院, 江苏 常熟 215500) \\ (3. 南京工程学院, 江苏 南京 211167)
}

周雪峰 ${ }^{1,2}$, 陈 光 $^{1}$, 冯亚亚 ${ }^{1}$, 祁志祥 ${ }^{1}$, 李 沛 $^{1}$, 成家林 ${ }^{3}$

(1. 南京理工大学 材料评价与设计教育部工程研究中心, 江苏 南京 210094)

摘 要: 研究了抽拉速率对一种镍基单晶高温合金组织和成分偏析的影响。结果表明：随着抽拉速率的提高，一次枝晶间距与二次枝晶 间距缩小, $\gamma^{\prime}$ 相尺寸减小; $\gamma / \gamma^{\prime}$ 共晶随着抽拉速率的提高, 尺寸变小, 但体积分数增加; 同时, 随着抽拉速率的提高, 单晶成分偏析增加。 关键词：镍基单晶高温合金; 抽拉速率; 凝固组织; 成分偏析

作者简介: 周雪峰, 男, 1979 年生, 博士生, 南京理工大学材料评价与设计教育部工程研究中心, 江苏 南京 210094 , 电话: 025-84315159, E-mail: cszhouxf@163.com 